\title{
Timely initiation of breastfeeding and associated factors among mothers of infants under 12 months in South Gondar zone, Amhara regional state, Ethiopia; 2013
}

\author{
Liyew Mekonen ${ }^{1 *}$, Wubareg Seifu ${ }^{2}$ and Zemenu Shiferaw ${ }^{1}$
}

\begin{abstract}
Background: Timely initiation of breastfeeding is defined as putting the newborn to the breast within one hour of birth. Significant benefits in reducing neonatal mortality and morbidity can be attained with effective promotion of timely initiation of breastfeeding and exclusive breastfeeding during the first months of life. Therefore, this study was conducted to assess timely initiation of breastfeeding and associated factors among mothers in South Gondar, Amhara regional state, Northern Ethiopia.
\end{abstract}

Methods: A community based cross-sectional study was employed. A multistage stratified sampling technique was used to select the sample of 845 mothers with $97.4 \%$ response rate. Moreover, data were collected by face to face interview using a semi structured questionnaire.

Result: The prevalence of timely initiation of breastfeeding was $48.7 \%$ (54.7\% in urban and $25.1 \%$ in rural areas). The odds of initiation of breastfeeding within one hour was higher for urban mothers (Adjusted Odds Ratio [AOR] 2.1; 95\% Confidence Interval [CI] 1.4, 3.3), multiparous mothers (AOR 2.8; 95\% Cl 2.0, 3.8), mothers who had antenatal care (AOR 3.2; 95\% Cl 2.0, 5.2), mothers delivered in health institution (AOR 3.1; $95 \% \mathrm{Cl} 2.2,4.6$ ) and mothers delivered vaginally (AOR $4.1 ; 95 \% \mathrm{Cl} 1.7,9.8$ ) than their respective counterparts.

Conclusion: This study depicts the rate of timely initiation of breastfeeding was low in south Gondar zone. Factors which were positively associated with timely initiation of breastfeeding include urban residence, multiparity, having antenatal care, mother deliver in health institution and vaginal mode of delivery. Therefore, South Gondar health office and healthcare providers have to provide breastfeeding information during antenatal care by giving special emphasis to rural and primiparous mothers in which timely initiation of breastfeeding is poorly practiced. Further study is needed to assess the implementation of policies on timely initiation of breastfeeding.

Keywords: Timely initiation, Breastfeeding, Associated factors, South Gondar, Ethiopia

\section{Background}

Timely initiation of breastfeeding is defined as putting the newborn to the breast within one hour of birth [1]. It was one the ten steps to successful breastfeeding on which the Baby Friendly Hospital Initiative was based and launched in 1992 [2]. Substantial benefits in reducing neonatal mortality and morbidity can be achieved with effective

\footnotetext{
* Correspondence: liy900@gmail.com

${ }^{1}$ College of Medicine and Health Sciences, Public Health Department, Reproductive Health and Nutrition Unit, Jigjiga University, Jigjiga, Ethiopia Full list of author information is available at the end of the article
}

promotion of timely initiation of breastfeeding and exclusive breastfeeding during the first months of life [3].

The World Health Organization (WHO) and United Nation Children's Fund (UNICEF) recommend initiation of breastfeeding within the first hour after birth and exclusive breastfeeding for the first six months followed by continued breastfeeding to age two years or beyond along with appropriate complementary feeding [4]. Despite these recommendations, only $39 \%$ of newborns in the developing world are put to the breast within one hour of birth, and only $37 \%$ of infants less than six months of age are exclusively breastfed [5].

(c) The Author(s). 2018 Open Access This article is distributed under the terms of the Creative Commons Attribution 4.0 International License (http://creativecommons.org/licenses/by/4.0/), which permits unrestricted use, distribution, and reproduction in any medium, provided you give appropriate credit to the original author(s) and the source, provide a link to the Creative Commons license, and indicate if changes were made. The Creative Commons Public Domain Dedication waiver (http://creativecommons.org/publicdomain/zero/1.0/) applies to the data made available in this article, unless otherwise stated. 
The Ethiopian government developed national infant and young child feeding guidelines in 2004 and has tried behaviour change communications on breastfeeding. There are considerable variations by region on timely initiation of breastfeeding, 60\% in Amhara region where South Gondar Zone is found and the highest in Dire Dawa regions and Harari $(90.5 \%$ and $89.4 \%$, respectively) $[6,7]$.

Therefore, this study addressed the issue of timely initiation of breastfeeding practice and associated factors in South Gondar Zone. The finding of this study can provide relevant information for future planning and interventions of appropriate strategies to promote the timely initiation of breastfeeding practices.

\section{Methods}

\section{Study setting}

The study was conducted in South Gondar Zone which is found in Amhara regional state located at $664 \mathrm{~km}$ from the capital city Addis Ababa. Based on the 2007 Census conducted by the Central Statistical Agency of Ethiopia, this zone had a total population of 2,051,738, of whom 1,041,061 were men and $1,010,677$ were women. A total of 468,238 households were counted in this zone, which results in an average of 4.38 persons to a household. There were 3953 mothers who had children aged less than 12 months at the time of the survey.

\section{Study design and sample}

A community based cross-sectional study was conducted among randomly selected 845 mothers of infants under 12 months in South Gondar Zone, Amhara Regional State, Ethiopia from March to May 2013. Mothers of infants under 12 months who were permanent residents were included. Mothers who were not available during data collection who were unconscious, critically ill and unable to respond were excluded from this study.

\section{Sample size determination}

The required sample size was determined using single population proportion formula with the following assumptions:

Level of confidence $=95 \%$

Type I error $(\alpha)=0.05$

$5 \%$ margin of error

Design effect $=2$ (Multi stage sampling)

Based on the assumption the prevalence of timely initiation of breastfeeding is $50 \%$.

$$
\begin{aligned}
& n=\frac{(Z a / 2) 2 \times P(1-P)}{d 2} \\
& n=\frac{(1.96) 2 \times 0.5(1-o .5)}{(0.05) 2} \\
& n=(384)
\end{aligned}
$$

Given 2 design effect and 10\% non-response rate, the final sample size was 845 .

\section{Sampling procedure}

A multistage random sampling technique was used for selecting mothers. There were 12 districts in South Gondar zone and from these four districts (Farta district, Estie district, Dera district, Fogera district) were selected by using a simple random sampling technique (lottery method). The sample size was proportionally allocated to the urban and rural kebeles based on the number of mothers who had infants less than 12 months. The sampling frame was prepared for both the urban and rural kebeles by doing census prior to the actual data collection period. Based on the census result there were 718 and 3235 mothers with infants less than 12 month in the rural and urban respectively. Finally 179 and 666 mothers who had infants less than 12 months were selected from rural and urban by using a computer-based generated random number respectively.

\section{Data collection and instrument}

Data were collected using structured and pretested interview questionnaires prepared from Ethiopian Demographic Health Survey and Linkage Project. Data collectors were given two days training for the questionnaires and interviewing techniques. The questionnaires were initially prepared for English and then have been translated into the local language, Amharic and again it was translated back into English to check its accuracy. The questionnaires were pretested and modified before the actual data collection. Four supervisors checked each completed questionnaire and principal investigator monitored the overall quality of the data collection.

\section{Operational definitions}

Early (timely) breastfeeding is defined as putting the newborn to the breast within one hour of birth.

Prelacteal feeding is feeding to an infant with something other than breast milk after birth to three days whereas ever breastfeeding is defined as mothers breastfeed their index baby.

Employed mothers defined as mothers that were employed in governmental, non governmental and private organization. 
Formal education defined as a person who attended primary or more education.

No formal education defined as a person who might able to write or read but did not attend primary or more education.

Marital status not in union comprised single, divorced, widow, cohabited and separated.

Information access if the mother read books, listen radio or watches a television program.

\section{Data processing and analysis}

Data were cleaned, edited, and entered onto Epidata version 3.2.1 and exported to the statistical packages for social sciences (SPSS) version 20 statistical software for further analysis. Frequency distribution and cross tabulation were done against the variables of interest. Bivariate analyses were done to assess the association between explanatory variables and outcome variable of the study. All variables with a $p$ - value of $<0.25$ at the bivariate analysis were included into multivariable logistic regression model in which odds ratio with $95 \%$ confidence intervals were estimated to identify independent predictors of timely initiation of breastfeeding. A $p$ - value less or equal to 0.05 were employed to declare the statistical significance.

\section{Results}

A total of 823 women were participating in this study and making the response rate of $97.4 \%$. The age of the respondents ranged from 15 to 49 with a mean ( \pm SD) age of 27 . 0 ( \pm 5.7$)$ years. Of the total 823 respondents, $656(79.7 \%)$ were urban dwellers. Majority 765 (93\%) of mothers was married, Christian by religion were $690(83.8 \%)$ and 819 (99.5\%) were in the Amhara ethnic group. Regarding educational status, 334 (40.6\%) of mothers had no formal education, 35\% (288) attended primary education and 24. $4 \%$ (201) respondents attended secondary and higher. Five hundred twelve (62.2\%) respondents were housewives. Four hundred and forty-three (53.8\%) index infants of mothers were male. The majority of the respondents 572 (69.5) had access to information (Table 1).

\section{Health service related and obstetrics characteristics}

The study revealed that $702(85.3 \%)$ mothers had antenatal care during their last pregnancy. Correspondingly, from all mothers were attending antenatal care, 451 (64. $2 \%)$ mothers were receiving any information related to breastfeeding by healthcare providers. Regarding place of the delivery, the mothers indicated that from the total sampled, the mothers $564(68.5 \%)$ gave birth in a health institution, $362(64.2 \%)$ occurred in the health centre and the rest $202(35.8 \%)$ were in a hospital. Four hundred nineteen $(74.3 \%)$ had postnatal counselling on breastfeeding among mothers gave birth in health institution.
Table 1 Sociodemographic characteristics of mothers with children less than 12 months in South Gondar Zone, Amhara regional state, Ethiopia, May $2013(n=823)$

\begin{tabular}{|c|c|c|}
\hline Variables & Frequency & $\overline{\text { Percent }}$ \\
\hline \multicolumn{3}{|l|}{ Age of mothers (year) } \\
\hline$<=20$ years & 109 & 13.2 \\
\hline $21-34$ years & 619 & 75.2 \\
\hline$>=35$ years & 95 & 11.5 \\
\hline \multicolumn{3}{|l|}{ Residence } \\
\hline Urban & 656 & 79.7 \\
\hline Rural & 167 & 20.3 \\
\hline \multicolumn{3}{|l|}{ Marital status } \\
\hline Union & 765 & 93.0 \\
\hline Not in union ${ }^{c}$ & 58 & 7.0 \\
\hline \multicolumn{3}{|l|}{ Religion } \\
\hline Christian & 690 & 83.8 \\
\hline Muslim & 133 & 16.2 \\
\hline \multicolumn{3}{|l|}{ Ethnicity } \\
\hline Amhara & 819 & 99.5 \\
\hline Tigray & 4 & 0.5 \\
\hline \multicolumn{3}{|l|}{ Maternal education } \\
\hline No formal education & 334 & 40.6 \\
\hline Primary education & 288 & 35.0 \\
\hline Secondary education or higher & 201 & 24.4 \\
\hline \multicolumn{3}{|l|}{ Occupation of the mother } \\
\hline Employed $^{\mathrm{a}}$ & 77 & 9.4 \\
\hline Unemployed $^{\mathrm{b}}$ & 746 & 90.6 \\
\hline \multicolumn{3}{|l|}{ Child's sex } \\
\hline Male & 443 & 53.8 \\
\hline Female & 380 & 46.2 \\
\hline \multicolumn{3}{|l|}{ Information access } \\
\hline Yes & 572 & 69.5 \\
\hline No & 251 & 30.5 \\
\hline
\end{tabular}

${ }^{a}$ Government organization employees, private organization employees

bHousewives, daily labourers, farmers, merchants, business owner, students 'Single, divorced, widow, cohabited, separated

Among 564 mothers who gave birth in the health institution, $315(55.9 \%)$ bathed their baby after $24 \mathrm{~h}$ and 189 (33.5\%) within two to $24 \mathrm{~h}$. This study showed that from the 259 (32.0\%) mothers who gave birth at home, 157 (60. $6 \%$ ) of them bathed their child within one hour after birth. Three hundred ninety-six (48.1\%) of the respondent were para I (primiparous mothers) and 189 (23.0\%) of them were para II. Regarding to the time of birth, 755 (91.7\%) of births were a term and $53(6.4 \%)$ were a post term. Concerning the mode of delivery from all respondents, 795 (96.6\%) had a vaginal delivery and 27 (3\%) had a caesarean section. 


\section{Breastfeeding related characteristics}

Mothers were asked about the time she decided to breastfeed their index child. The response revealed that 505 (61.4\%) decided to breastfeed their infants before they became pregnant, 183 (22.2\%) decided after delivery and the rest 135 (16.4\%) decided during the pregnancy. All mother's breastfed their index child. Out of all, 808 (98.2\%) mothers were breastfeeding their infants at the time of interview. Two hundred and ninety (35.2\%) mothers expressed and discarded the first milk (colostrum) before they gave their breast milk for their index child. The most common reason for colostrum expulsion was 'it is dirty' 122 (42.1\%) followed by, it creates abdominal pain $80(27.6 \%)$ and open the closed nipple 45 (15.5\%). One hundred seventy-four (21.1\%) mothers introduced prelacteal foods or fluids to their infants. The most common prelacteal food was butter which is reported by 129 (74.1\%) of breastfeeding mothers followed by sugar solution 18 (10.3\%) and cow milk 15 (8.6\%).

\section{Initiation of breastfeeding}

The proportion of mothers who initiated breastfeeding within one hour differ by residence which was 359 (54. $7 \%$ ) within urban and 42 (25.1\%) within rural (Fig. 1).

\section{Factor influencing timely initiation of breastfeeding}

Using multivariate analysis; residence, parity, antenatal care, place of delivery and mode of delivery were identified as an independent predictor for timely initiation of breastfeeding among mothers in South Gondar Zone. Many of independent variables which showed statistical significance with the outcome variables in the bivariate analysis remained significantly associated with outcome variable in multivariate analysis (Tables 2 and 3). In this regard, the odds initiation of breastfeeding within one hour increased for urban mothers (Adjusted Odds Ratio [AOR] 2.1; 95\% Confidence Interval $[\mathrm{CI}] 1.4,3.3)$, for multiparous mothers (AOR 2.8; 95\% CI 2.0, 3.8), for mothers who had antenatal care (AOR 3.2; 95\% CI 2.0, 5.2), among mothers delivered in a health institution (AOR 3.1; 95\% CI 2.2, 4.6) and for mothers who delivered vaginally (AOR 4.1; 95\% CI 1.7, 9.8) with their respective counterparts (Table 4).

\section{Discussion}

The rate of timely initiation of breastfeeding in this study was $48.7 \%$. It was consistent to findings in Brazil (47.1\%) and in Ethiopia Goba Woreda (52.4\%) $[8,9]$. However this was much lower than findings in Nepal (72.7\%), Ethiopia Arjo Woreda 62.6\% and south Gondar zone Farta district (76.7\%) [10-12]. The prevalence of timely initiation of breastfeeding in this study was (48.7\%) higher than in Amhara region (38\%) [7].
In this study, 290 (35.2\%) respondents expressed and discarded the first milk (colostrum) before starting to breastfeed for their index child. It was consistent with the study conducted in northern part of Ethiopia where colostrum was said to cause abdominal problems, but discarding a portion was sufficient to mitigate this effect [13]. However, according to a study conducted in western Nepal, a significant portion of mothers gave colostrum or breast milk as the first meal to 332 (86.2\%) babies, while the remaining 54 (14\%) babies were given a fluid other than breast milk as their first feed [10].

This study revealed that $174(21.1 \%)$ mothers were introducing prelacteal foods or fluids to their child. The prevalence of the prelacteal feeding practice in the current study is higher than national findings where the proportion of women who gave prelacteal feeding within the first three days of life was 13\% [14]. Another study conducted in the rural northern part of Ethiopia showed that the majority of mothers practiced ritual prelacteal feeding [13]. In addition, in this study, the common prelacteal food introduced to the newborn baby was butter in $129(74.1 \%)$ followed by sugar solution 18 (10.3\%) and cow milk in 15 (8.6\%). It was consistent with research findings in Mekele town which revealed the common prelacteal food introduced for the newborn babies was butter followed by sugar solution and cow milk [15].

Timely initiation of breastfeeding is influenced by varied and complex interrelated factors and multivariate logistic analysis showed that the odds of timely initiation of breastfeeding among mothers who had antenatal care was increased 3.2 times compared to mothers who had no antenatal care. Correspondingly, mothers that received antenatal care have relative reduced risks of about $8 \%$ of delaying breastfeeding initiation than mothers without antenatal care [16]. The possible reason could be that pregnant women who had antenatal care might be informed about timely initiation of breastfeeding by healthcare providers.

The odds of timely initiation of breastfeeding among mothers increased 3.1 times among mothers who had an institutional delivery compared with mothers who delivered at home. A similar study indicated that mothers who delivered their babies at home have an increased relative risk of about $12 \%$ of delaying early initiation of breastfeeding than mothers who delivered in the hospitals (or clinics) [16]. This can be explained as mothers who gave birth in health institution had healthcare provider support which helped to initiate breastfeeding timely.

In the current study, the odds of timely initiation increased 4.1 times when mothers delivered vaginally than mothers delivered through caesarean section. It is similar to a study conducted in Nigeria which says mothers that were delivered of their babies through caesarean section 
Table 2 Bivariate analysis shows the association between sociodemographic characteristics with initiation of breastfeeding among mothers in South Gondar zone, Amhara regional state, Ethiopia, May 2013

\begin{tabular}{|c|c|c|c|c|}
\hline \multirow{2}{*}{$\begin{array}{l}\text { Sociodemographic } \\
\text { variable }\end{array}$} & \multicolumn{4}{|c|}{ Initiation of breastfeeding } \\
\hline & $\leq 1 \mathrm{~h}$ & $>1 \mathrm{~h}$ & $p$-value & COR $(95 \% \mathrm{Cl})$ \\
\hline \multicolumn{5}{|l|}{ Age of the mother (years) } \\
\hline$<=20$ years & $37(33.9 \%)$ & $72(66.1 \%)$ & & \\
\hline 20-34 years & $320(51.7 \%)$ & $299(48.3 \%)$ & 0.001 & $2.1(1.4,3.2)$ \\
\hline$>=35$ years & $44(46.3 \%)$ & $51(53.7 \%)$ & 0.073 & $1.7(1.0,3.0)$ \\
\hline \multicolumn{5}{|l|}{ Residence } \\
\hline Urban & $359(54.7 \%)$ & $297(45.3 \%)$ & 0.000 & $3.6(2.5,5.3)$ \\
\hline Rural & $42(25.1 \%)$ & $125(74.9 \%)$ & & \\
\hline \multicolumn{5}{|l|}{ Marital status } \\
\hline Married & $373(48.8 \%)$ & $392(51.2 \%)$ & 0.944 & $1.0(0.6,1.7)$ \\
\hline Others & $28(48.3 \%)$ & $30(51.2 \%)$ & & \\
\hline \multicolumn{5}{|l|}{ Maternal education } \\
\hline Formal education & $252(51.5 \%)$ & $237(48.5 \%)$ & 0.051 & $1.3(1.0,1.8)$ \\
\hline No formal education & $149(44.65)$ & $185(55.4 \%)$ & & \\
\hline \multicolumn{5}{|l|}{ Religion } \\
\hline Orthodox & $339(49.3 \%)$ & $349(50.7 \%)$ & 0.477 & $0.9(0.6,1.3)$ \\
\hline Others $^{c}$ & $62(45.9 \%)$ & $73(54.1 \%)$ & & \\
\hline \multicolumn{5}{|l|}{ Ethnicity } \\
\hline Amhara & $399(48.7 \%)$ & $420(51.3 \%)$ & 0.959 & $0.95(0.1,6.8)$ \\
\hline Tigray & $2(50.0 \%)$ & $2(50.0 \%)$ & & \\
\hline \multicolumn{5}{|l|}{ Occupation of the mother } \\
\hline Employed $^{a}$ & $41(53.2 \%)$ & $36(46.8 \%)$ & 0.405 & $1.2(0.8,1.9)$ \\
\hline Unemployed $^{\mathrm{b}}$ & $360(48.3 \%)$ & $386(51.7 \%)$ & & \\
\hline \multicolumn{5}{|l|}{ Information access } \\
\hline Yes & $312(54.6 \%)$ & $259(45.4 \%)$ & 0.000 & $2.2(1.6,3.0)$ \\
\hline No & $89(35.3 \%)$ & $163(64.7 \%)$ & & \\
\hline \multicolumn{5}{|l|}{ Child's sex } \\
\hline Male & $214(48.3 \%)$ & $229(51.7 \%)$ & 0.796 & $0.96(0.7,1.3)$ \\
\hline Female & 187 (49.2\%) & $193(50.8 \%)$ & & \\
\hline
\end{tabular}

${ }^{a}$ Government organization employee, private organization employee

${ }^{b}$ Student, daily labourer, housewife, farmer, business owner merchant

cMuslim, protestant

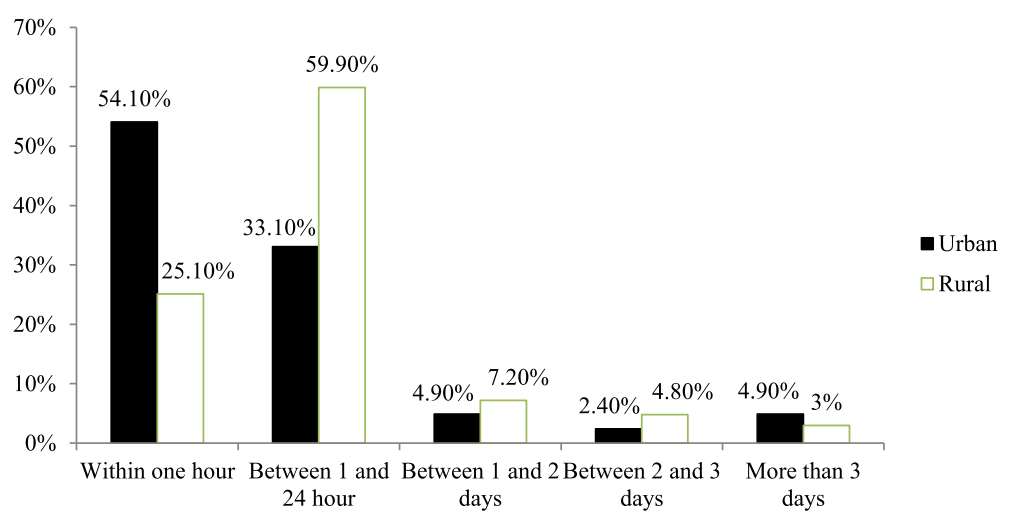

Fig. 1 Distribution of breastfeeding initiation by place of residence among mothers in South Gondar zone, Amhara regional state, Ethiopia, May 2013 
Table 3 Bivariate analysis shows the association between health service related and obstetrics characteristics with initiation of breastfeeding among mothers in South Gondar Zone, Amhara regional state, Ethiopia, May 2013

\begin{tabular}{|c|c|c|c|c|}
\hline \multirow[t]{2}{*}{ Variables } & \multicolumn{4}{|c|}{ Initiation of breastfeeding } \\
\hline & $\leq 1 \mathrm{~h}$ & $>1 \mathrm{~h}$ & $p$-value & Crude Odds Ratio $(95 \% \mathrm{Cl})$ \\
\hline \multicolumn{5}{|l|}{ Parity } \\
\hline Multiparous & $238(55.7 \%)$ & $189(44.3 \%)$ & 0.000 & $1.8(1.4,2.4)$ \\
\hline Primiparous & $163(41.2 \%)$ & $233(58.8 \%)$ & & 1 \\
\hline \multicolumn{5}{|l|}{ Antenatal care } \\
\hline Yes & $370(52.7 \%)$ & $332(47.3 \%)$ & 0.000 & $3.2(2.1,5.0)$ \\
\hline No & $31(25.6 \%)$ & $90(74.4 \%)$ & & 1 \\
\hline \multicolumn{5}{|l|}{ Time of birth } \\
\hline Term & $369(48.9 \%)$ & $386(51.1 \%)$ & 0.774 & $1.1(0.7,1.8)$ \\
\hline Others $^{\mathrm{a}}$ & $32(47.1 \%)$ & $36(52.9 \%)$ & & 1 \\
\hline \multicolumn{5}{|l|}{ Place of delivery } \\
\hline Health Institution & $329(58.3 \%)$ & $235(41.7 \%)$ & 0.000 & $3.6(2.6,5.0)$ \\
\hline Home & $72(27.8 \%)$ & $187(72.2 \%)$ & & 1 \\
\hline \multicolumn{5}{|l|}{ Mode of delivery } \\
\hline Vaginal & $393(49.4 \%)$ & $403(50.6 \%)$ & 0.049 & $2.3(1.0,5.4)$ \\
\hline Caesarean section & $8(29.6 \%)$ & 19 (70.4\%) & & 1 \\
\hline \multicolumn{5}{|l|}{ Child bathing } \\
\hline Within one hour & 99 (45.6\%) & $118(54.4 \%)$ & 0.287 & $0.9(0.6,1.2)$ \\
\hline More than one hour & $302(49.8 \%)$ & $304(50.2 \%)$ & & 1 \\
\hline
\end{tabular}

COR Crude odds ratio, $\mathrm{Cl}$ Confidence interval, preterm, post term ${ }^{\mathrm{a}}$

Table 4 Multivariate logistic regression showing factors independently associated with initiation of breastfeeding among mothers in the south Gondar zone, Amhara regional state, Ethiopia, May 2013

\begin{tabular}{|c|c|c|c|c|}
\hline \multirow[t]{2}{*}{ Variables } & \multicolumn{4}{|c|}{ Initiation of breastfeeding } \\
\hline & $\leq 1 \mathrm{~h}$ & $>1 \mathrm{~h}$ & COR $(95 \% \mathrm{Cl})$ & AOR $(95 \% \mathrm{Cl})$ \\
\hline \multicolumn{5}{|l|}{ Residence } \\
\hline Urban & $359(54.7 \%)$ & $297(45.3 \%)$ & $3.6(2.5,5.3)$ & $2.1(1.4,3.3)$ \\
\hline Rural & $42(25.1 \%)$ & 125 (74.9\%) & 1 & 1 \\
\hline \multicolumn{5}{|l|}{ Parity } \\
\hline Multiparous & $238(55.7 \%)$ & 189 (44.3\%) & $1.8(1.4,2.4)$ & $2.8(2.0,3.8)$ \\
\hline Primiparous & $163(41.2 \%)$ & $233(58.8 \%)$ & 1 & 1 \\
\hline \multicolumn{5}{|l|}{ Antenatal care } \\
\hline Yes & $370(52.7 \%)$ & $332(47.3 \%)$ & $3.2(2.1,5.0)$ & $3.2(2.0,5.2)$ \\
\hline No & $31(25.6 \%)$ & $90(74.4 \%)$ & 1 & 1 \\
\hline \multicolumn{5}{|l|}{ Place of delivery } \\
\hline Health institution & $329(58.3 \%)$ & $235(41.7 \%)$ & $3.6(2.6,5.0)$ & $3.1(2.24 .6)$ \\
\hline Home & $72(27.8 \%)$ & 187 (72.2\%) & 1 & 1 \\
\hline \multicolumn{5}{|l|}{ Mode of delivery } \\
\hline Vaginal & $393(49.4 \%)$ & $403(50.6 \%)$ & $2.3(1.0,5.4)$ & $4.1(1.7,9.8)$ \\
\hline Caesarean section & 8 (29.6\%) & 19 (70.4\%) & 1 & 1 \\
\hline
\end{tabular}


have about $58 \%$ increased the risk of delaying the early introduction of the first breast milk to their babies as compared to mothers who had a vaginal (normal) delivery [17]. In addition, a systematic review of 53 studies revealed that rates of early breastfeeding (any initiation or at hospital discharge) were lower after caesarean delivery compared with after vaginal delivery [18].

The odds of timely initiation of breastfeeding increased 2.1 times for mothers who resided in an urban than in rural area. Similarly, a study conducted in Ethiopia Goba district showed that urban dwellers were three times more likely to practice timely initiation of breastfeeding when compared to their rural counterparts [9]. In contrast, a study conducted in Al-Hassa province, Saudi Arabia showed that rural mothers were 4.2 times more likely to initiate breastfeeding within one hour [17]. In the current study, the lower rate of timely initiation of breastfeeding in rural areas was probably the traditional practice in the areas; such as early child bathing, colostrum expulsion and prelacteal feeding.

The odds of timely initiation of breastfeeding increased 2.8 times among multiparous mothers than primiparous mothers. In the same way, a study conducted in Turkey showed that breastfeeding initiation was later in primiparous mothers than in mothers who are multiparous [19].

\section{Conclusions}

This study shows that the rate of timely initiation of breastfeeding was low in south Gondar zone. Factors which were positively associated with timely initiation of breastfeeding include urban residence, multiparty, having antenatal care, mother deliver in health institution and vaginal mode of delivery. Therefore, South Gondar health office and healthcare providers have to provide breastfeeding information during antenatal care by giving special emphasis to rural and primiparous mothers where timely initiation of breastfeeding is poorly practiced. Further study is needed to assess the implementation of policies on timely initiation of breastfeeding.

\section{Abbreviations}

AOR: Adjusted Odds Ratio; Cl: Confidence Interval; COR: Crude Odds Ratio; SPSS: Statistical Package for Social Science; UNICEF: United Nation Children's Fund; WHO: World Health Organization

\section{Acknowledgements}

We would like to express our deepest gratitude to Jimma University and South Gondar health bureau for their facilitation during this study. We are also extremely grateful to the data collectors, supervisors and study participants.

\section{Availability of data and materials}

The data of this study available from the corresponding author and will be avail on reasonable request.

\section{Authors' contributions}

LM conceived and designed the study, performed analysis and interpretation of data and drafted the first manuscript. WS and ZS participated in the critical review of the subsequent draft of the manuscript. All authors read and approved the final manuscript for publication.

\section{Ethics approval and consent to participate}

The ethical approval and clearance for the study before data collection were obtained from Jimma University College of public health and medicine research ethical clearance board. Official letters were obtained from South Gondar zone health office and each study districts health bureau. At the time of data collection, Informed consent was obtained from the respondents after explaining the purpose of the study.

\section{Competing interests}

The authors declare that they have no competing interests.

\section{Publisher's Note}

Springer Nature remains neutral with regard to jurisdictional claims in published maps and institutional affiliations.

\section{Author details}

${ }^{1}$ College of Medicine and Health Sciences, Public Health Department, Reproductive Health and Nutrition Unit, Jigjiga University, Jigjiga, Ethiopia. ${ }^{2}$ College of Medicine and Health Sciences, Public Health Department, Epidemiology and Biostatistics Unit, Jigjiga University, Jigjiga, Ethiopia.

Received: 9 July 2017 Accepted: 23 April 2018

Published online: 02 May 2018

\section{References}

1. World Health Organization, UNICEF. Indicators for assessing infant and young child feeding practices part 3: country profiles. Geneva: WHO. available at http://apps.who.int/iris/bitstream/handle/10665/44368/\%209789241599757_ eng.pdf;jsessionid=47902C5018B04906526317E6DB2699D7? sequence $=1$.

2. Gupta A. Initiating breastfeeding within one hour of birth. World Alliance for Breastfeeding Action. 2007;1:1-6.

3. Khan J, Vesel $L$, Bahl R, Martines JC. Timing of breastfeeding initiation and exclusivity of breastfeeding during the first month of life: effects on neonatal mortality and morbidity - a systematic review and meta-analysis. Maternal Child Health J. 2015;19:468-79.

4. WHO. Global strategy for infant and young child feeding. Geneva: WHO; 2003.

5. United Nations Children's Fund. Tracking progress on child and maternal nutrition a survival and development priority. New York: UNICEF; 2009. Available at: https://www.unicef.org/publications/files/Tracking_Progress_ on_Child_and_Maternal_Nutrition_EN_110309.pdf.

6. Federal Ministry of Health Family Health Department Ethiopia. National Strategy on Infant and Young Child Feeding, 2004.

7. Central Statistical Agency [Ethiopia] and ICF International. 2012. Ethiopia demographic and health survey 2011. Addis Ababa, Ethiopia and Calverton, Maryland, USA: Central Statistical Agency and ICF International.

8. Vieira TO, Vieira GO, Giugliani ERJ, Mendes CM, Martins CC, Silva LR. Determinants of breastfeeding initiation within the first hour of life in a Brazilian population. BMC Public Health. 2010;10:760.

9. Setegn T, Gerbaba M, Belachew T. Determinants of timely initiation of breastfeeding among mothers in Goba Woreda, south East Ethiopia: a cross sectional study. BMC Public Health. 2011;11:217.

10. Chandrashekhar TS, Joshi HS, Binu V, Shankar PR, Rana MS, Ramachandran U. Breastfeeding initiation and determinants of exclusive breastfeeding- a questionnaire survey in an urban population of western Nepal. Public Health Nutr. 2007:5:21

11. Dessalegn T, Tefera B, Eskindir L, Shikur M. Sub-optimal breastfeeding of infantsduring the first six months and associated factors. BMC Public Health. 2012:12:363.

12. Donald T. Whitson. Farta Child Survival XVIII Project Final Evaluation CARE Ethiopia, 2007. file:///C:/Users/Sue/AppData/Local/Microsoft/Windows/ INetCache/IE/QM9YZJ1P/eth-farta-child-survival-final-dec-07.pdf.

13. Rogers NL, Abdi J, Moore D, Nd'iangui S, Smith $\sqcup$, Carlson AJ, et al. Colostrum avoidance, prelacteal feeding and late breast-feeding initiation in rural northern Ethiopia. Public Health Nutr. 2011;14:2029-36.

14. Alemayehu T, Haidar J, Habte D. Determinants of exclusive breastfeeding practices in Ethiopia. Ethiop J Health Dev. 2009;23:12-8. 
15. Berhe H, Mekonnen B, Bayray A, Berhe H. Determinants of breast feeding practices among mothers attending public health facilities, Mekelle, northern Ethiopia; a cross sectional study. Int J Pharm Sci Res. 2013;4:650-60.

16. El-Gilany AH, Sarraf B, Al-Wehady A. Factors associated with timely initiation of breastfeeding in Al-Hassa province, Saudi Arabia. East Mediterr Health J. 2012;18:250-4

17. Athavale AV, Athavale SA, Deshpande SG, Zodpey SP, Sangole S. Initiation of breast-feeding by urban women. Health and Population; Perspectives and Issues. 2004;27:117-25.

18. Emily P, Shalini S, Chris G, Lara H, Neena M, Matthew J. Breastfeeding after cesarean delivery: a systematic review and meta-analysis of world literature. Am J Clin Nutr. 2012;95:1113-35.

19. Orün E, Yalçin SS, Madendağ Y, Ustünyurt-Eras Z, Kutluk S, Yurdakök K. Factors associated with breastfeeding initiation time in a baby-friendly hospital. Turk J Pediatr. 2010:52:10-6.

Ready to submit your research? Choose BMC and benefit from:

- fast, convenient online submission

- thorough peer review by experienced researchers in your field

- rapid publication on acceptance

- support for research data, including large and complex data types

- gold Open Access which fosters wider collaboration and increased citations

- maximum visibility for your research: over $100 \mathrm{M}$ website views per year 